\title{
Corrosion failure analysis of hearing aid battery-spring contacts
}

\section{Gudla, Visweswara Chakravarthy; Ambat, Rajan}

\section{Published in:}

Engineering Failure Analysis

Link to article, DOI:

10.1016/j.engfailanal.2017.05.045

Publication date:

2017

Document Version

Peer reviewed version

Link back to DTU Orbit

Citation (APA):

Gudla, V. C., \& Ambat, R. (2017). Corrosion failure analysis of hearing aid battery-spring contacts. Engineering Failure Analysis, 79, 980-987. https://doi.org/10.1016/j.engfailanal.2017.05.045

\section{General rights}

Copyright and moral rights for the publications made accessible in the public portal are retained by the authors and/or other copyright owners and it is a condition of accessing publications that users recognise and abide by the legal requirements associated with these rights.

- Users may download and print one copy of any publication from the public portal for the purpose of private study or research.

- You may not further distribute the material or use it for any profit-making activity or commercial gain

- You may freely distribute the URL identifying the publication in the public portal

If you believe that this document breaches copyright please contact us providing details, and we will remove access to the work immediately and investigate your claim. 


\section{Accepted Manuscript}

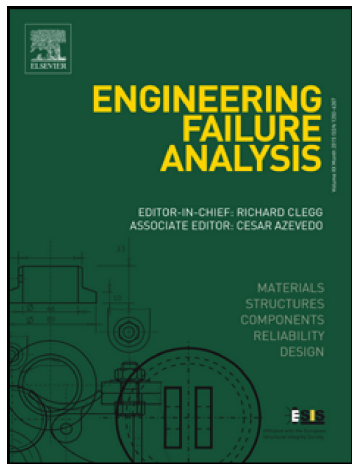

Visweswara Chakravarthy Gudla, Rajan Ambat

PII: $\quad$ S1350-6307(16)30821-4

DOI: $\quad$ doi: $10.1016 /$ j.engfailanal.2017.05.045

Reference: $\quad$ EFA 3165

To appear in: $\quad$ Engineering Failure Analysis

Received date: 3 October 2016

Revised date: $\quad 27$ January 2017

Accepted date: 31 May 2017

Please cite this article as: Visweswara Chakravarthy Gudla, Rajan Ambat, Corrosion failure analysis of hearing aid battery-spring contacts, Engineering Failure Analysis (2017), doi: 10.1016/j.engfailanal.2017.05.045

This is a PDF file of an unedited manuscript that has been accepted for publication. As a service to our customers we are providing this early version of the manuscript. The manuscript will undergo copyediting, typesetting, and review of the resulting proof before it is published in its final form. Please note that during the production process errors may be discovered which could affect the content, and all legal disclaimers that apply to the journal pertain. 


\title{
Corrosion Failure Analysis of Hearing Aid Battery-Spring Contacts
}

\author{
Visweswara Chakravarthy Gudla*, Rajan Ambat \\ Section of Materials and Surface Technology, Department of Mechanical Engineering, \\ Technical University of Denmark, 2800 Kgs. Lyngby, Denmark, *vichg@mek.dtu.dk
}

\begin{abstract}
Reliability of low power electrical contacts such as those in hearing aid battery-spring systems is a very critical aspect for the overall performance of the device. These systems are exposed to certain harsh environments like high humidity and elevated temperatures, and often in combination with high levels of salt from human perspiration and environmental pollutants. In addition, the design aspects of such systems often call for multi-material combinations of substrate and coatings for catering to various requirements such as electrical conductivity and wear resistance, which in turn enhance the susceptibility of these systems to galvanic corrosion. In this study, traditional behind the ear (BTE) hearing aid systems, which failed during service were analysed. Failure analysis was performed on the dome type batteryspring contact systems. The morphology of the contact areas was observed using scanning electron microscopy, and the compositional analysis of the corrosion products and contaminants was performed using energy dispersive X-ray spectroscopy. Wear track morphology was observed on the contact points, and the top coating on the dome was worn out exposing the substrate spring material. The obtained results were correlated to the underlying corrosion mechanism and the failure mode is presented.
\end{abstract}


Keywords: Chloride; Coating failures; Corrosion; Environmental interaction; Failure analysis.

\section{Introduction}

Modern day hearing aids are generally very reliable and durable in their performance. However, certain harsh environments, such as places with high humidity and elevated temperatures, often combined with increased levels of perspiration from the user and earwax can impair the functionality of the devices [1] [2] [3] [4] [5] [6]. Electrical contacts (low power) in these devices are critical components, which limit the hearing aid performance in such situations, leading to reduced battery life, power dropouts and increased acoustic feedback (whistling) in the device output [7]. Currently, majority of the electrical contacts systems are based on traditional electro/electroless plated $\mathrm{Ni} / \mathrm{Au}$-systems (see Figure 1); however, this system is very sensitive to wear of the Au-top layer, corrosion of the underlying Ni layer and of the substrate material [8,9]. Increasing the thickness of the top Au layer is not usually recommended due to the steep increase in cost of the contact system. On the contrary, the current trend is to reduce the thickness of the top Au layer to reduce product cost, but the increase in porosity due to pinholes sets a limit on the down gauging of the Au layer thickness [10]. Reduced $\mathrm{Au}$ layer thickness also exposes both the $\mathrm{Ni}$ interlayer and the substrate underneath. This study analyses the in-service corrosion failure of such low power battery spring contacts used in behind-the-ear hearing aid devices. The spring surfaces have been characterized using scanning electron microscopy combined with elemental analysis by EDS and the underlying failure mechanisms are presented and discussed. Failure analysis of five spring contacts is presented in this paper.

\section{Here Figure 1}




\section{Materials and Methods}

Behind the ear hearing aid devices installed with Au plated battery spring contacts were obtained from the field after being in service for different periods. The metal spring contacts were then carefully separated from the rest of the device and were prepared for analysis of the contact surface (see Figure 2). The springs are numbered sequentially as Contact-1, Conatct2, Contact-3, Contact-4, and Contact-5. The separated springs were then mounted for electron microscopy observations onto an Aluminium stub, and painted with conductive Ag paint around the edges to prevent charging. Scanning electron microscopy was performed on the contact surfaces using a SEM Quanta 200 ESEM with Oxford X-max EDS capability. In addition, selected areas were subjected to focused ion beam milling for in-situ observation of the cross sections using a Helios Nanolab dual beam FEG SEM.

\section{Here Figure 2}

\section{Results and Discussion}

\section{Here Figure 3}

The Au plated Contact-1 surface shown in Figure 3 displayed no features that correspond to general wear or corrosion of the contact surface. The Au plating was found to be intact, however presence of organic compounds as contamination was observed. The EDS analysis (see Table 1) of this contamination shows presence of high amounts of $\mathrm{C}, \mathrm{F}$ ad $\mathrm{Si}$ in addition to traces of $\mathrm{K}$ and $\mathrm{Na}$. In contrast, the dome surface of Contact-2 clearly displayed delamination of the applied Au plating at the contact point as seen in Figure 4. In addition, the exposed substrate displayed wear track morphology. This is due to the repeated wiping motion that occurs while changing the battery during the service of the device. Organic 
contamination containing $\mathrm{C}, \mathrm{O}, \mathrm{F}, \mathrm{Al}$, and $\mathrm{Si}$ was detected on the exposed substrate surface of the contacts (see Table 1).

\section{Here Figure 4}

The Contact-3 surface showed no delamination of the Au plating, but displayed wear out of the Au plating resulting in exposure of the underlying substrate (see Figure 5). Severe organic contamination was observed on the hemispherical dome. The EDS analysis showed that it consisted of $\mathrm{C}, \mathrm{O}, \mathrm{Na}, \mathrm{Mg}, \mathrm{Al} \mathrm{Si}, \mathrm{S}, \mathrm{Cl}$ in addition to the elements from substrate material which is a Ni-based material (similar composition for Contact-2 substrate, see Table 1). In addition, several locations displayed features corresponding to corrosion and associated corrosion products as shown in Figure 5 (b). Heavy corrosion products with mud crack morphology were observed. In order to get a better overview of the nature and composition of the corrosion products, an EDS elemental mapping was carried out on the area shown in Figure 5 (b) (see Figure 6).

\section{Here Figure 5}

\section{Here Table 1}

The EDS elemental maps for corroded region on Contact-3 (shown in Figure 5 (b)) are shown in Figure 6 . The bright appearing surface in the secondary electron image corresponds to the Au plating which also shows presence of Co. Cobalt is generally added to Au plating baths to obtain hard Au coating with better mechanical properties compared to the pure Au which is softer [11]. In addition to $\mathrm{Ni}$ from the substrate, $\mathrm{Fe}$ also is present, which is an alloying element for the Ni-based substrate alloy. However, the distribution of Fe does not follow that of $\mathrm{Ni}$. A closer observation at the distribution of Fe shows that it follows the distribution of $\mathrm{O}$ suggesting the presence of $\mathrm{Fe}-\mathrm{O}$ based phases like $\mathrm{Fe}_{2} \mathrm{O}_{3}$ or $\mathrm{Fe}_{3} \mathrm{O}_{4}$ (corrosion product, Rust). In addition, the maps for $\mathrm{C}, \mathrm{Si}$, and $\mathrm{F}$ follow each other and this is attributed to the organic contamination that has been observed on the surfaces of various contacts as 
discussed earlier. Other elements such as $\mathrm{Na}, \mathrm{K}, \mathrm{Al}$, and $\mathrm{Ca}$ along with $\mathrm{Cl}$ are detected, which suggest the presence of salts and silicates arising from the atmosphere in the form of mist, dust particles and/or from human perspiration.

\section{Here Figure 6}

Figure 7 shows the corrosion and contamination on Contact-4 surface. Corrosion products were observed at the contact surface and in addition, crystals of salts based on chlorides of $\mathrm{Na}$ and $\mathrm{K}$ were detected as seen in Figure 7 (c) (see Table 1 for composition). The Au plating appeared to be intact all over the surface of the contact with exception to the contact point as seen in Figure 7 (b). However, a closer look at the surface morphology of the Au reveals that there are a huge number of pores in the Au surface (see Figure 7 (d)). The origin of these pores can be attributed to either inherent porosity in the Au plating or due to corrosive attack by the salts that are found on the contact surface.

\section{Here Figure 7}

Focused ion beam cross-sections prepared on the corroded contact surface show that even though the top Au plating is intact in certain locations, corrosion has propagated way below the surface of the contact. Figure 8 shows two such instances where a portion of the $\mathrm{Au}$ coating is still intact, but the underlying $\mathrm{Ni}$ underlayer, and the $\mathrm{Ni}$ substrate have been severely corroded. This is evident from the difference in morphology compared to the substrate Ni alloy and the corroded areas. The EDS elemental maps performed on these corroded areas below the Au plating showed presence of $\mathrm{Ni}, \mathrm{O}$, and $\mathrm{Cl}$ in the corroded region below the $\mathrm{Au}$ plating (see Figure 9). Iron was also detected (not shown in map) in the corroded region of the substrate in addition to $\mathrm{Ni}$ and $\mathrm{O}$, which is expected as the substrate contains Fe.

\section{Here Figure 8}




\section{Here Figure 9}

The several features observed on the various contacts and the related elements in the corrosion products can be assigned to various external and internal factors in the service of the hearing aid devices. Mostly the features observed correspond to degradation due to wear and/or corrosion of the contact points. Wear of electrical contacts can take place by various modes like adhesive, abrasive, delamination, corrosive, and fretting wear [12]. Of these various modes, fretting wear is of specific importance and manifests itself in forms of metal debris particles, wear scars, corrosion products, cracked surface oxide or sulphide films and polymer formation from atmospheric organic products. The morphology observed on Contact-2 and Contact-3 in Figure 4 and Figure 5 suggests it is due to wear. In addition, the polymeric compounds containing $\mathrm{C}, \mathrm{O}, \mathrm{Si}$, and $\mathrm{F}$ found at the contact points could be due to contamination or in certain cases polymerization of atmospheric organic precursors during wear. However, the presence of fluorine in these polymeric compounds suggests that the contamination arises from a fluoropolymer (fluorocarbon resin), which is widely used to cover the electronic circuitry as a conformal coating (25-125 $\mu \mathrm{m}$ thick) to protect the components from external conditions such as moisture, dust, chemicals, salt spray, and temperature extremes [13]. Elements such as $\mathrm{Na}, \mathrm{K}$, and $\mathrm{Cl}$ arise from the salt spray from the atmosphere as well as human perspiration in behind-the-ear (BTE) hearing aid devices [14]. Potassium can also enter the hearing aid device due to leak from a faulty battery ( $\mathrm{Zn}$ air button batteries containing $\mathrm{KOH}[15-17])$. Other elements such as $\mathrm{Ca}, \mathrm{Al}$, and $\mathrm{Mg}$ in combination with $\mathrm{Si}$ and $\mathrm{O}$ are assigned to dust particles, which are usually silicates and contain some salts and soot from atmopsheric pollutants and other media $[18,19]$.

The EDS observations in Table 1 reveal that the corrosion products usually contain Ni. $\mathrm{Fe}$ and $\mathrm{O}$ in addition to $\mathrm{Na}, \mathrm{K}$ and $\mathrm{Cl}$ as well as $\mathrm{C}, \mathrm{O}, \mathrm{Si}$ and $\mathrm{F}$ suggesting that the corrosion is 
caused by the halides such as $\mathrm{F}$ and $\mathrm{Cl}$ in this case. As mentioned earlier, $\mathrm{F}$ arises from fluoropolymers, which are used as conformal coatings. However, these fluoropolymers are generally chemically very stable in most of the organic solvents, acids and bases [20]. Even though there is a good correlation between the corrosion products and presence of $\mathrm{F}$ from the conformal coating, it is safe to assume that $\mathrm{F}$ from the conformal coating does not initiate or assist in corrosion of the contact metals. This is attributed to the good stability of the conformal coating material owing to high electronegativity of $\mathrm{F}$ [21]. Certain fluoropolymers have been shown to have some or little degradation at room temperature in highly alkaline environments such as concentrated $\mathrm{NaOH}$ and $\mathrm{KOH}(\mathrm{pH}>10)$ causing deterioration in their chemical and mechanical properties [22]. Hence, the release of elemental $F$ from fluoropolymers, which can cause corrosion is only possible under highly alkaline conditions. However, this might be possible due to the presence of $\mathrm{KOH}$ from the $\mathrm{Zn}$ air batteries. Under such situations, the degradation of metal contact can occurs due to $\mathrm{F}$ as well as the leaked $\mathrm{KOH}$ from the faulty batteries $[23,24]$. In general cases, where faulty battery is not an issue, corrosion or degradation is expected to be caused by $\mathrm{Cl}$ from the salts of $\mathrm{Na}$ and $\mathrm{K}$ in the atmosphere, human perspiration and dust particles (see Figure 7 (c)). Atmospheric dust carries several components in it, and their presence and relative concentration depend highly on the geographical areas where they are generated. Dust particles usually contain hygroscopic species, which attract moisture and thus result in the formation of a conductive water layer even when the relative humidity is lower than the critical RH levels $[25,26]$. In addition, dust particles that contain hard compounds act as abrasive particles at the mating interfaces of the contacts leading to ploughing and gouging of the softer surfaces [12].

All the above-mentioned processes and factors together with humidity lead to the formation of good electrolyte layers for the formation of corrosion cells. Gold plated surfaces are prone to inherent porosity (pinholes) at low plating thicknesses and thus enable access of 
electrolyte to the underlying not so noble metals like Ni (see Figure 7 (d)) causing 'pore corrosion'. This causes corrosion of the underlying material that is accelerated due to the galvanic coupling between a small active metal surface (anodic site) at the bottom of the pore and a high surface area of noble metal (cathodic sites). Severe localised corrosion of the underlying metal results in volume expansion and forms halos around the pinhole on the surface of the gold, and in extreme cases total delamination of the top gold layer $[10,27,28]$. The presence of corrosion under the top gold layer in Figure 8 is a manifestation of severe underlying metal corrosion due to pores in the gold layer.

During service, low-power battery spring contacts are designed to exert a certain force on the battery counter face in order to maintain electrical contact. This force is in certain situations enough to break though thin and brittle surface oxides and corrosion products to maintain electrical contact. In such situations, when the underlying metal is corroded away due to pore corrosion, the force exerted increases due to thickening of corrosion products. This causes cracking and delamination of the top gold layer due to weakened underlying metal or substrate and allows very easy access for the corrosive species to the active material, which is supposed to be protected by the top gold plated layer (see Figure 4 (a) and Figure 7 (b)). Upon delamination and cracking, the corrosion then proceeds fast and results in steep increase in electrical resistance of the contact due to severe corrosion product formation due to the insulating behaviour and finally causes total device failure. In terms of failure analysis, the corrosion products covering the contact surface after catastrophic failure usually mask the evidence of corrosion initiation like pore corrosion stains on gold surface and wear tracks at contact surface due to fretting or delamination.

In summary, among the hearing aid battery spring contacts analysed in this investigation, the corrosion and degradation is caused by a combination of several factors 
ranging from wear, dust corrosion, atmospheric pollutants, human perspiration, and leakage from faulty batteries.

\section{Conclusions}

- Gold plated low-power battery spring contacts showed degradation of the contact surface due to corrosion, wear, and delamination.

- Organic contaminants based of C-O-Si-F from the fluoropolymer conformal coating were observed on the contact surface.

- Corrosion products with compounds of $\mathrm{Ni}, \mathrm{Fe}-\mathrm{O}$ and $\mathrm{Cl}$ were observed along with salts of $\mathrm{Na}$ and $\mathrm{K}$ arising from human perspiration and atmospheric contaminants.

- Severe corrosion of the spring coating as well as base material was observed in the case of high presence of $\mathrm{K}$ due to leakage of hearing aid battery.

- Corrosion of the underlying Ni layer and the Ni based alloy substrate was observed deep into the substrate material. .

- Environmental factors as well as internal defects were responsible for the tribological and corrosion failure of the gold plated battery spring contacts.

\section{Acknowledgements}

This work was supported by the Danish Agency for Science, Technology, and Innovation, Ministry of Science, Innovation, and higher education under the project 'High Performance Electrical Contacts (HiPEC)'. The authors would like to acknowledge all the project partners. 


\section{$\underline{\text { References }}$}

[1] R. Ambat, Climatic Reliability of Electronic Devices and Components, SMT Surf. Mt. Technol. Mag. 29 (2014) 12-28.

[2] M.S. Jellesen, V. Verdingovas, H. Conseil, K. Piotrowska, R. Ambat, Corrosion in electronics : Overview of failures and countermeasures, in: Proc. Eurocorr 2014, 2014: pp. $1-10$.

[3] H. Conseil, V.C. Gudla, M.S. Jellesen, R. Ambat, Humidity Build-Up in a Typical Electronic Enclosure Exposed to Cycling Conditions and Effect on Corrosion Reliability, IEEE Trans. Components, Packag. Manuf. Technol. (2016) 1-10. doi:10.1109/TCPMT.2016.2590779.

[4] M.S. Jellesen, D. Minzari, U. Rathinavelu, P. Moller, R. Ambat, Corrosion in Electronics at Device Level, in: ECS Trans., The Electrochemical Society, 2010: pp. 114. doi:10.1149/1.3321952.

[5] M.S. Jellesen, D. Minzari, U. Rathinavelu, P. Møller, R. Ambat, Corrosion failure due to flux residues in an electronic add-on device, Eng. Fail. Anal. 17 (2010) 1263-1272. doi:10.1016/j.engfailanal.2010.02.010.

[6] R. Ambat, Guest editorial Corrosion reliability of electronic devices, Corros. Eng. Sci. Technol. 48 (2013) 408-408. doi:10.1179/1478422X13Z.000000000169.

[7] Z.-G. Kong, L.-J. Xu, Morphology and electrical contact properties of electrical connection materials in corrosive atmosphere, Rare Met. 32 (2013) 174-178. doi:10.1007/s12598-013-0032-2. 
[8] S. Koford, Environmental effects on connector reliability, in: 1991 Proc. 41st Electron. Components Technol. Conf., IEEE, 1991: pp. 215-217. doi:10.1109/ECTC.1991.163879.

[9] W. Reyes, E. Peter, G. Bolger, C. Sie, Factors Influencing Thin Gold Performance for Separable Connectors, IEEE Trans. Components, Hybrids, Manuf. Technol. 4 (1981) 499-508. doi:10.1109/TCHMT.1981.1135843.

[10] X.-Y. Xue-Yan Lin, Y.-L. Yi-Lin Zhou, J.-G. Ji-Gao Zhang, Island growth of corroded products on various plated surfaces after long-term indoor air exposure in China, in: Electr. Contacts - 1999. Proc. Forty-Fifth IEEE Holm Conf. Electr. Contacts (Cat. No.99CB36343), IEEE, 1999: pp. 153-161. doi:10.1109/HOLM.1999.795942.

[11] Y. Okinaka, M. Hoshino, Some recent topics in gold plating for electronics applications, Gold Bull. 31 (1998) 3-13. doi:10.1007/BF03215469.

[12] M. Ohring, Chapter 9 - Degradation of Contacts and Package Interconnections, in: Reliab. Fail. Electron. Mater. Devices, 1998: pp. 475-537. doi:10.1016/B978012524985-0/50010-6.

[13] M.L. Minges, ASM, Electronic materials handbook. - 1: Packaging, Illustrate, ASM Intermational, 1989.

[14] B.A. McSwiney, The Composition of Human Perspiration (Samuel Hyde Memorial Lecture): (Section of Physical Medicine),, Proc. R. Soc. Med. 27 (1934) 839-48. http://www.ncbi.nlm.nih.gov/pubmed/19989792 (accessed June 21, 2016).

[15] D. Lee, J. Fu, Z. Chen, Advanced Materials for Zn-Air Rechargeable Batteries, in: 2015: pp. 171-182. doi:10.1201/b19061-11.

[16] Y. Li, H. Dai, Recent advances in zinc-air batteries, Chem. Soc. Rev. 43 (2014) 52575275. doi:10.1039/C4CS00015C.

[17] R.A. Powers, Batteries for low power electronics, Proc. IEEE. 83 (1995) 687-693. 
doi:10.1109/5.371974.

[18] Y.N. Liang, J.G. Zhang, J.J. Liu, Identification of inorganic compounds of dust and their effects on electrical contact failure, in: Electr. Contacts, 1997., Proc. Forty-Third IEEE Holm Conf., IEEE, 1997: pp. 315-327.

[19] J. Zhang, Y.-N. Liang, J.-W. Wan, B.-S. Sun, Analysis of compounds in airborne dust collected in Beijing, in: Electr. Contacts, 1998. Proc. Forty-Fourth IEEE Holm Conf., IEEE, 1998: pp. 166-171.

[20] J.J. Licari, J.J. Licari, 2 - Chemistry and Properties of Polymer Coatings, in: Coat. Mater. Electron. Appl., 2003: pp. 65-200. doi:10.1016/B978-081551492-3.50004-0.

[21] L.W. McKeen, 11 - Fluorinated Coatings: Technology, History, and Applications, in: Introd. to Fluoropolymers, 2013: pp. 231-276. doi:10.1016/B978-1-4557-7442$5.00011-5$.

[22] D. Cheneler, J. Bowen, S.D. Evans, M. Górzny, M.J. Adams, M.C.L. Ward, Characteristics and durability of fluoropolymer thin films, Polym. Degrad. Stab. 96 (2011) 561-565. doi:10.1016/j.polymdegradstab.2010.12.022.

[23] S.P. Penteado, R. Ferreira Bento, Performance analysis of ten brands of batteries for hearing aids, Int. Arch. Otorhinolaryngol. Int. Arch. Otorhinolaryngol. 17 (n.d.). doi:10.7162/S1809-977720130003000010.

[24] Y. Xu, X. Xu, G. Li, Z. Zhang, G. Hu, Y. Zheng, Experimental Research of Liquid Infiltration and Leakage in Zinc Air Battery, Int. J. Electrochem. Sci. 8 (2013) 1180511813. www.electrochemsci.org (accessed June 17, 2016).

[25] G. Kulwanoski, M. Gaynes, A. Smith, B. Darrow, Electrical contact failure mechanisms relevant to electronic packages, in: Electr. Contacts - 1991 Proc. ThirtySeventh IEEE HOLM Conf. Electr. Contacts, IEEE, 1991: pp. 184-192. doi:10.1109/HOLM.1991.170823. 
[26] Xue-Yan Lin, Ji-Gao Zhang, Dust corrosion, in: Proc. 50th IEEE Holm Conf. Electr. Contacts 22nd Int. Conf. Electr. Contacts Electr. Contacts, 2004., IEEE, n.d.: pp. 255262. doi:10.1109/HOLM.2004.1353127.

[27] T. Shintani, Corrosion mechanism analysis of salt spray test and sulfur dioxide test on gold plated connector contact, IEICE Trans. Electron. E81-C (1998) 356-361.

[28] Xue-Yan Lin, Ji-Gao Zhang, Properties of corrosion stains on thin gold plating, in: Proc. Forty-Eighth IEEE Holm Conf. Electr. Contacts, IEEE, n.d.: pp. 156-162. doi:10.1109/HOLM.2002.1040836. 


\section{Figure Captions}

Figure 1: Illustration of currently used battery spring system and typical multi-layer coating used.

Figure 2: Photograph showing a representative Au plated spring contact separated from the rest of the hearing aid device.

Figure 3: Secondary electron image showing: (a) hemispherical dome Contact-1 and (b) contamination at the Contact-1 surface.

Figure 4: Secondary electron image showing: (a) delamination of Au coating on Contact-2 and (b) contamination on the exposed substrate in Contact-2.

Figure 5: Secondary electron image showing: (a) wear of Au coating on Contact-3 with exposed substrate and severe contamination on the dome, and (b) severe corrosion of the Au coated spring material in Contact-3.

Figure 6: Secondary electron image and EDS elemental maps of the corroded surface region on Contact-3.

Figure 7: Secondary electron image showing: (a) delamination of Au coating and corrosion on Contact-4, (b) corrosion products, corroded substrate and contamination on the exposed substrate region in Contact-4, (c) crystals of salt on the Contact-4 surface and (d) pores in the surface of the Au plating.

Figure 8: FIB cross-section of (a) Contact-4 and (b) Contact-5 showing propagation of corrosion under the Au plating.

Figure 9: EDS elemental maps of the corroded region in the Ni substrate below the Au plating showing oxides and chlorides as corrosion products. 


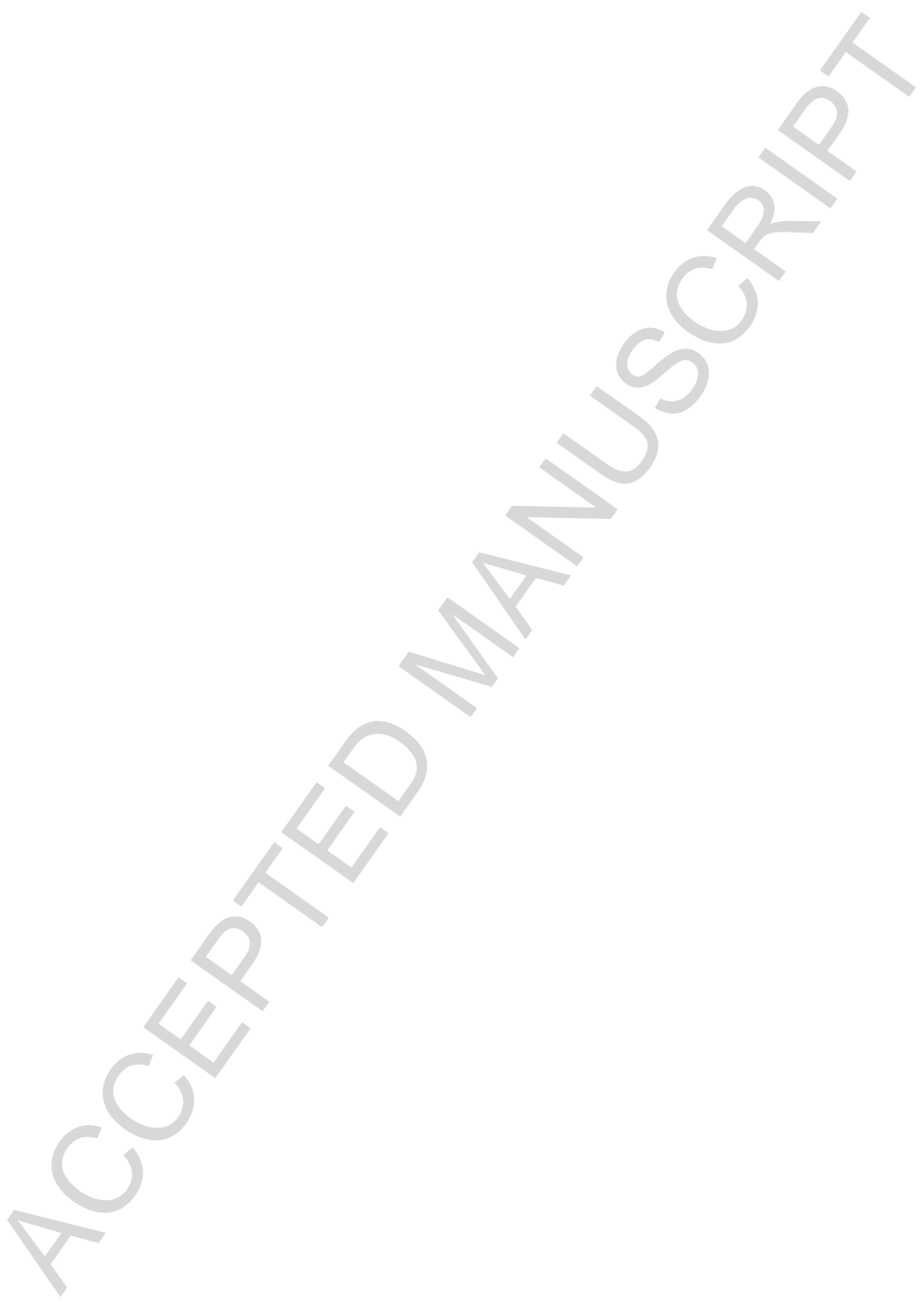




\section{Hearing aid battery contact and battery schematic}

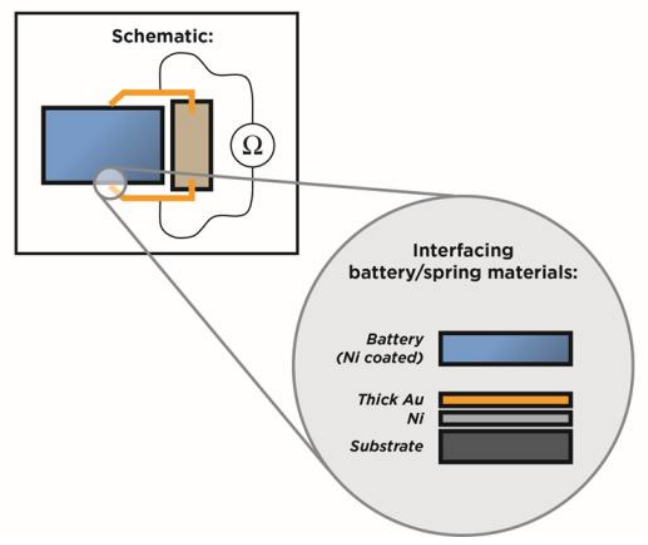

Figure 1: Illustration of currently used battery spring system and typical multi-layer coating used. 


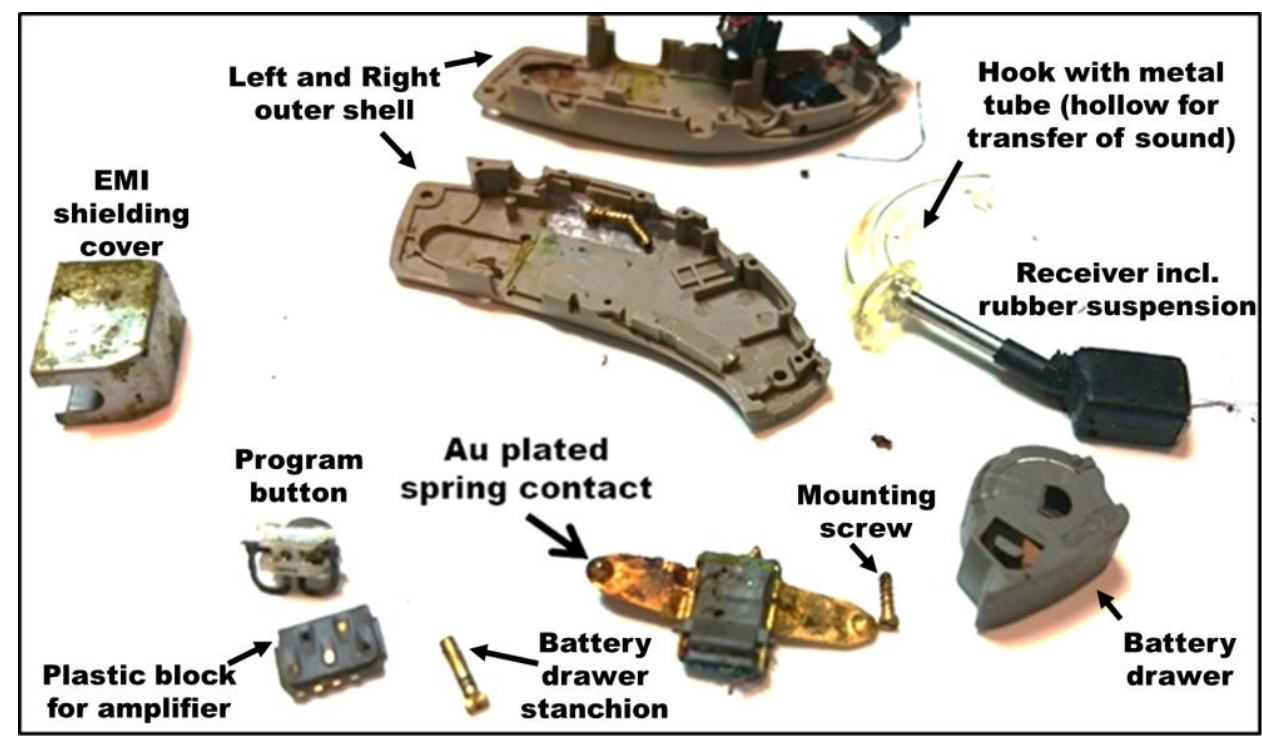

Figure 2: Photograph showing a representative Au plated spring contact separated from the rest of the hearing aid device. 

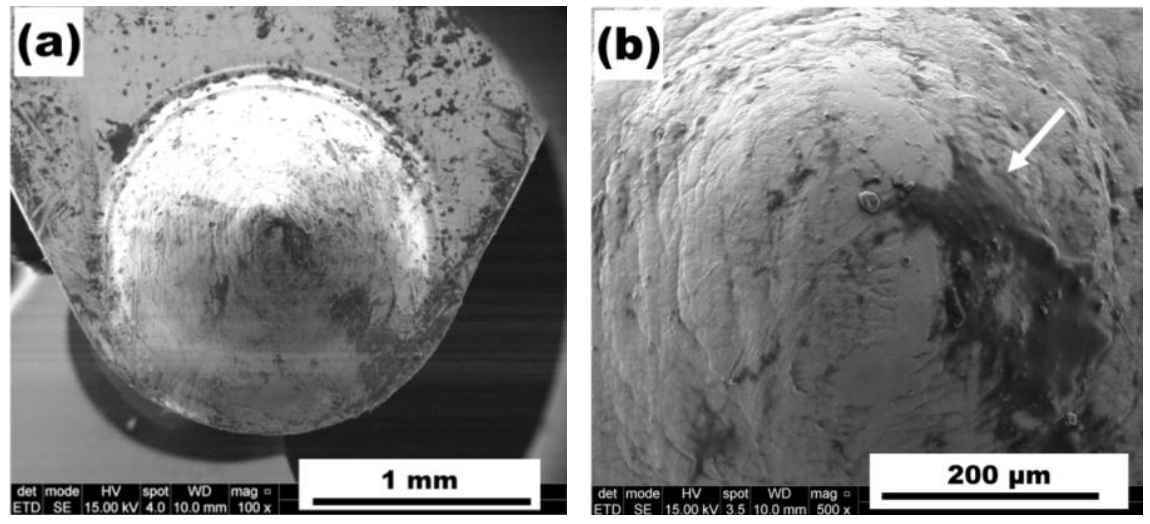

Figure 3: Secondary electron image showing: (a) hemispherical dome Contact-1 and (b) contamination at the Contact-1 surface. 

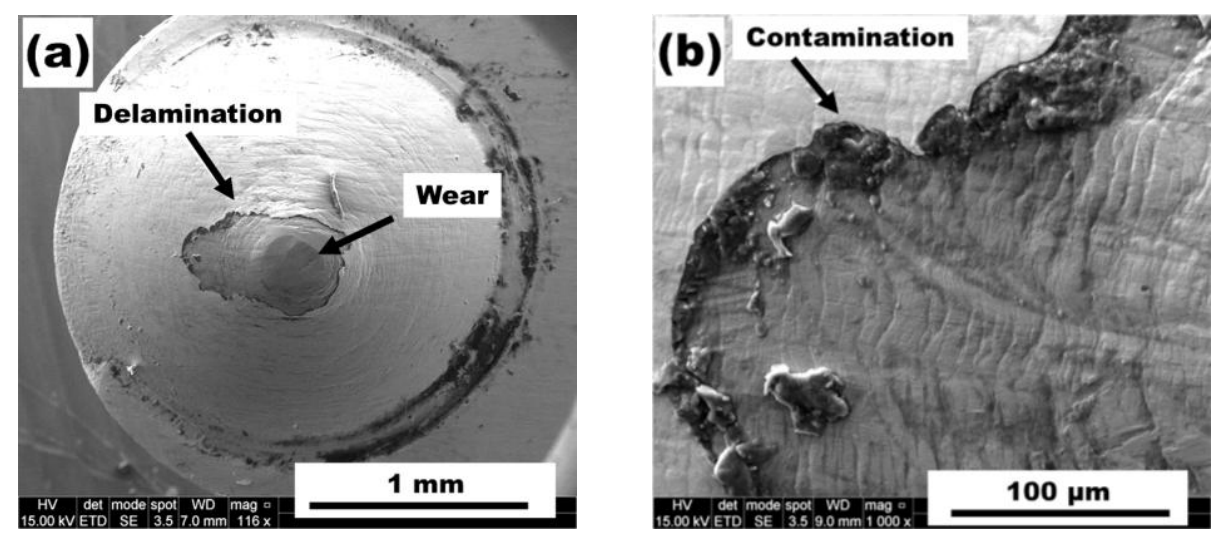

Figure 4: Secondary electron image showing: (a) delamination of Au coating on Contact-2 and (b) contamination on the exposed substrate in Contact-2. 

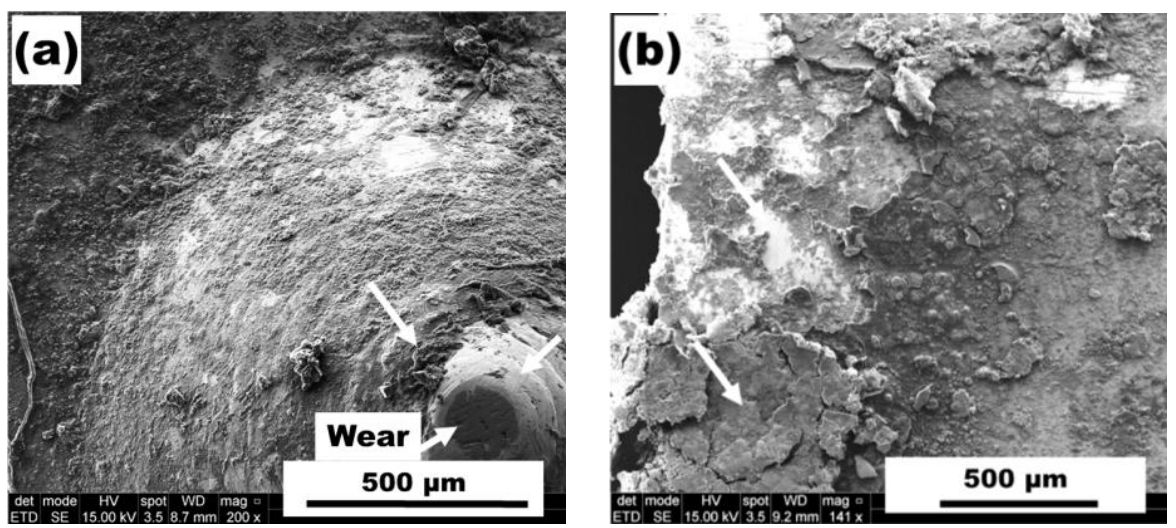

Figure 5: Secondary electron image showing: (a) wear of Au coating on Contact-3 with exposed substrate and severe contamination on the dome, and (b) severe corrosion of the Au coated spring material in Contact-3. 


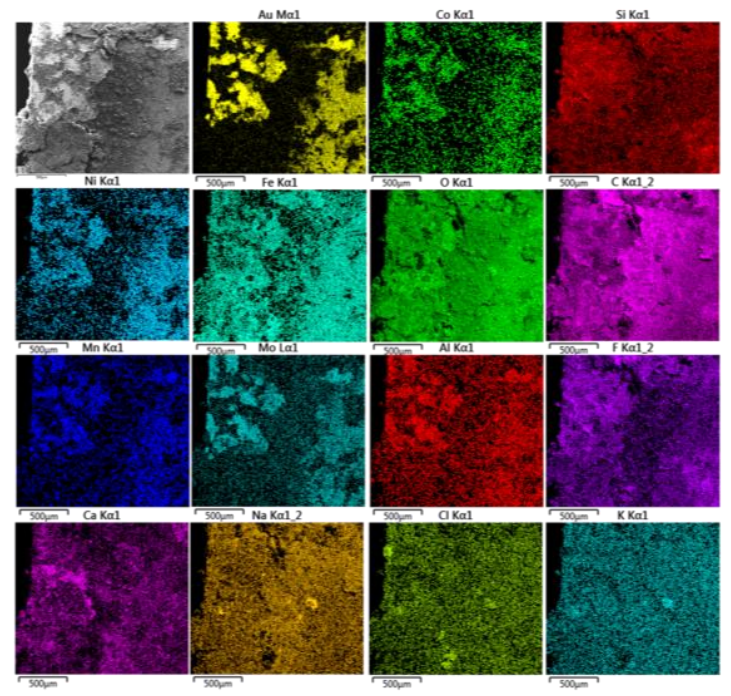

Figure 6: Secondary electron image and EDS elemental maps of the corroded surface region on Contact-3. 

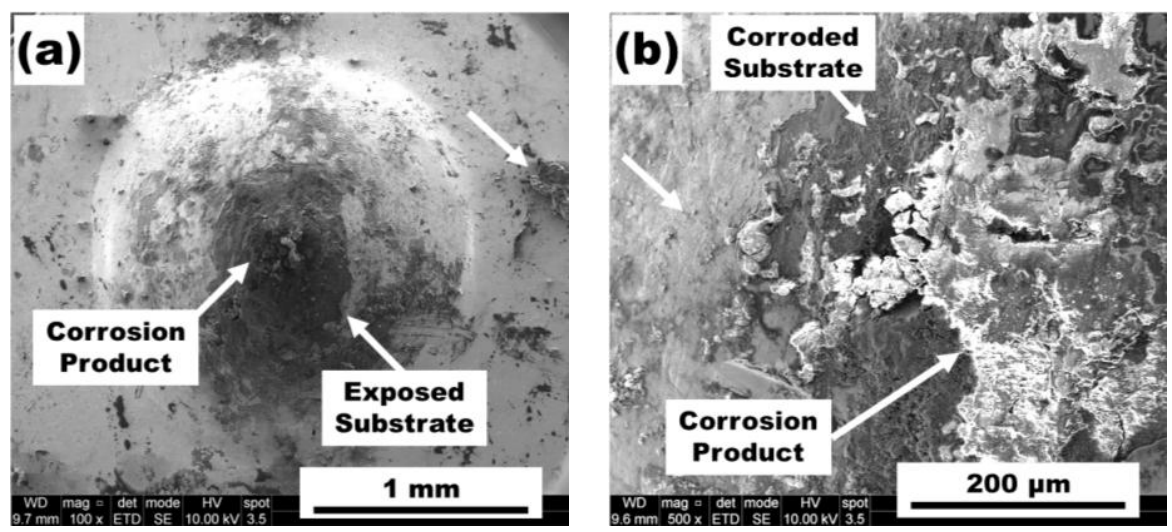

Figure 7: Secondary electron image showing: (a) delamination of Au coating and corrosion on Contact-4, (b) corrosion products, corroded substrate and contamination on the exposed substrate region in Contact-4, (c) crystals of salt on the Contact-4 surface and (d) pores in the surface of the Au plating. 

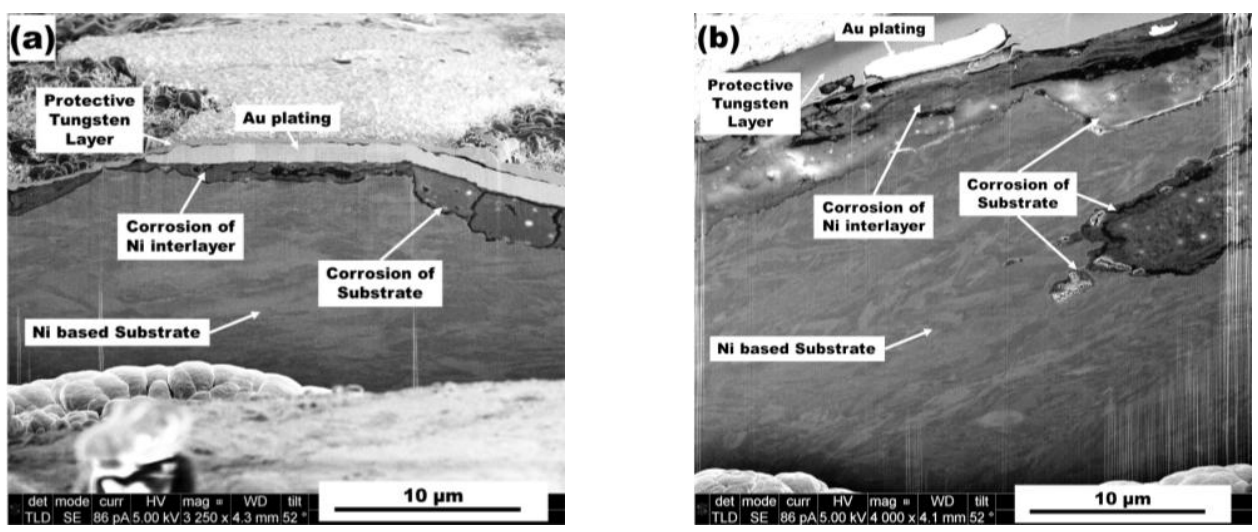

Figure 8: FIB cross-section of (a) Contact-4 and (b) Contact-5 showing propagation of corrosion under the Au plating. 


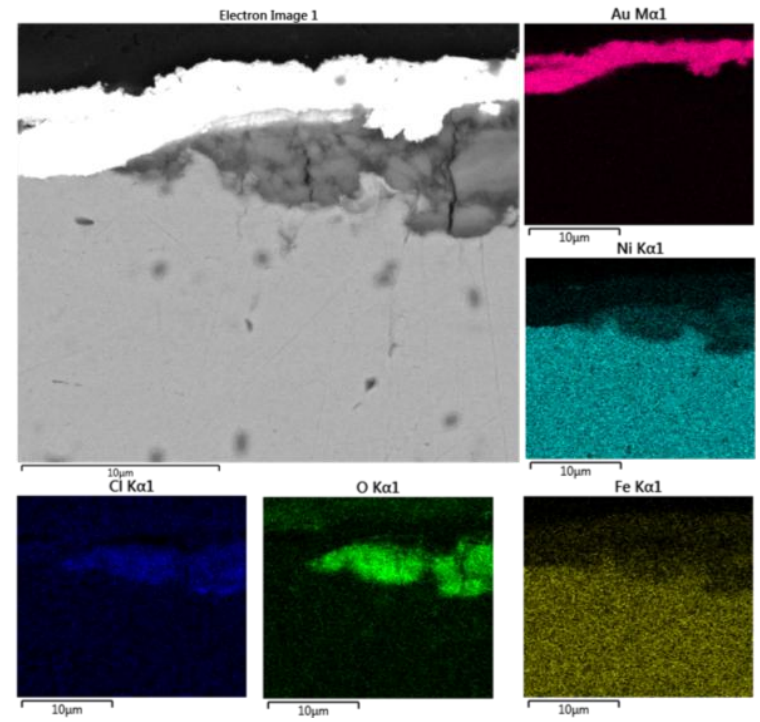

Figure 9: EDS elemental maps of the corroded region in the Ni substrate below the Au plating showing oxides and chlorides as corrosion products. 


\section{$\underline{\text { Table Captions }}$}

Table 1: EDS elemental composition of various features observed on the spring contact surfaces.

\begin{tabular}{|c|c|c|c|c|c|c|c|c|c|c|c|c|c|c|c|c|c|}
\hline & Fig. & $\mathbf{C}$ & $\mathbf{N}$ & $\mathbf{O}$ & $\mathbf{F}$ & $\mathbf{N a}$ & Mg & Al & $\mathbf{S i}$ & $\mathbf{S}$ & Cl & $\mathbf{K}$ & $\mathbf{C a}$ & $\mathrm{Fe}$ & $\mathrm{Ni}$ & $\mathbf{C u}$ & Au \\
\hline Contamination & $3(b)$ & 45.9 & 2.4 & 11 & 27.7 & 0.2 & & & 10.5 & & & 0.2 & & & & & 2.06 \\
\hline Au coating & $3(b)$ & 9.48 & & 0.85 & 1.01 & & & & & & & & & & & & 88.7 \\
\hline Contamination & $4(b)$ & 56.3 & & 17.6 & 6.68 & 0.7 & & & 2.37 & 0.8 & 0.4 & 0.4 & & 1.1 & 7.7 & 1.4 & 4.66 \\
\hline Au coating & $4(b)$ & 16.1 & & 3.79 & 2.13 & & & 1 & 0.42 & & & & & & 0.46 & & 76 \\
\hline Au Coating & $5(a)$ & 20.8 & & 2.89 & 2.83 & & & & 0.56 & & & 0.2 & & & & & 72.8 \\
\hline $\begin{array}{c}\text { Contamination } \\
\text { on Dome }\end{array}$ & $5(a)$ & 43.2 & & 31.9 & & 7. & 0.6 & 0.3 & 0.97 & 0.4 & 1.7 & 3.2 & 1.7 & 3.8 & 1.09 & & 3.69 \\
\hline Salt Crystals & $7(c)$ & 24.4 & & 31.8 & & 7.4 & & & & & 1.9 & 2 & & & 27.4 & & 4.99 \\
\hline
\end{tabular}




\section{Highlights}

- Corrosion and wear was observed on failed hearing aid battery spring contacts.

- Contacts were observed to have an electroplated Au layer on a Ni underlayer.

- Corrosion products contained oxides and chlorides of $\mathrm{Ni}$ and Fe.

- Delamination of Au layer and wear of underlying Ni based substrate occurred.

- Human perspiration, dust, organic contamination and faulty batteries caused failure. 